\section{Verbete impresso ou verbete digital? Eis a questão}

Printed version or digital entry? That is the question

Halysson Oliveira DANTAS (UFC) halysson_dantas@hotmail.com

Recebido em: 27 de set. de 2020. Aceito em: 19 de out. de 2020.

\section{(1)}

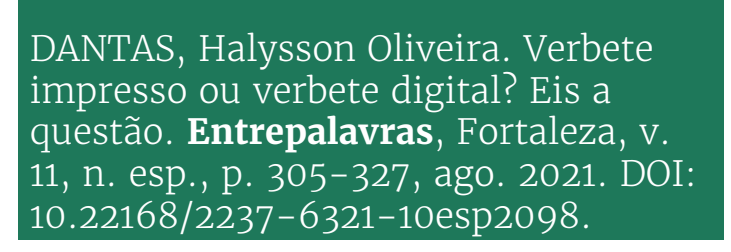

Resumo: Este artigo argui sobre o possível percurso de reelaboração do gênero verbete do meio impresso para o digital. Tal ponderação leva em conta os preceitos da metalexicografia, o conceito de colônia discursiva (HOEY, 2001), bem como os construtos teórico-metodológicos da Teoria do Hipertexto Digital. A partir da análise contrastiva de dicionários impressos e de dicionários eletrônicos on-line, essencialmente medioestrutural, delineia-se, com base nas evidências atuais, que, aparentemente, seja um pouco cedo para definir que o gênero verbete digital seja uma reelaboração do verbete impresso. Denota-se, pois, um processo de automatização da consulta que, por desrespeitar certos princípios da Lexicografia, tem contribuído mais para o insucesso da demanda dos consulentes do que o contrário, sobretudo, em relação a estudantes.

Palavras-chave: Metalexicografia. Dicionário eletrônico. Verbete. 


\section{v. 11 (esp.)}

305-327 ago. 2021

Abstract: This article argues about the possible course of reelaboration of the genre entry of the print medium to digital. Such a consideration takes into account precepts of metalexicography, the concept of discursive colony (HOEY, 2001), as well as the theoretical-methodological constructs of Digital Hypertext Theory. From the contrastive analysis of printed dictionaries and electronic dictionaries online, essentially mediostructural, we outline, based on the current evidence, that it seems a little early to define that the genre digital entry is a reworking of the printed entry. In fact, it is a process of automation of the consultation that, for disrespecting certain principles of lexicography, has contributed more to the failure of the demand of the consultants than the opposite, especially in relation to students.

Keywords: Metalexicography. Dictionary. Entry.

\section{Introdução}

As discussões acerca dos avanços tecnológicos e suas influências no ensino têm tomado, cada vez mais, fôlego tanto no âmbito da academia quanto do espaço escolar. O crescimento das Tecnologias da Informação e Comunicação (TIC) nas mais diversas atividades humanas evidencia não só o estabelecimento de um novo aporte técnico-científico que favorece o desempenho de certas atividades, como também acarreta uma mudança de comportamentos sociais e individuais.

Na contramão dessa avalanche tecnológica que vem largamente se expandindo em nossa sociedade, vozes tradicionalistas rechaçam a utilização das TIC em substituição ao esforço individual humano, sob o argumento de que tal substituição redundará na perda de habilidades físicas e intelectuais que a humanidade levou séculos para adquirir, a exemplo da tecnologia escrita.

Especificamente no caso dos dicionários, o conhecimento prévio sobre como consultá-los é condição sine qua non para o sucesso da consulta, sobretudo para os estudantes (DANTAS, 2009). Portanto, considerando que o dicionário é uma colônia discursiva (HOEY, 2001) com características próprias e que cumpre uma função social (PONTES, 2009), é preciso levar em conta que este tipo de obra, seja impressa, seja digital, tem de estar em consonância com os preceitos da lexicografia, de modo a favorecer o sucesso da consulta do usuário, adequando-se ao perfil deste.

Desta feita, tendo como ponto de partida as contribuições teórico-metodológicas da metalexicografia e dos estudos sobre o hipertexto digital, formulamos a seguinte questão de investigação, norteadora deste trabalho: de que forma o fluxo da informação 
nos dicionários digitais revela seu projeto lexicográfico, denotando algum tipo de reelaboração do gênero verbete digital em relação ao impresso?

Esta inquirição parte do princípio de que o dicionário se configura como uma colônia discursiva (HOEY, 2001) composta por gêneros discursivos que, embora tenham conteúdo proposicional, propósito comunicativo e estilos diferentes, inter-relacionam-se, tornando a obra lexicográfica um todo coeso e coerente. No entanto, tal organização típica dos dicionários proporciona, com o leitor/ consulente, uma relação bastante peculiar: uma dinâmica de leitura/ consulta própria, o que desempenha um papel muito relevante para o aprendizado escolar, devendo o uso do dicionário configurar-se como uma prática tão comum nas classes quanto o uso do livro didático.

Nesse sentido, propomos discutir, de forma contrastiva, a organização medioestrutural de dicionários impressos e dicionários eletrônicos on-line e suas implicações para uma possível reelaboração do gênero verbete.

Ao longo deste artigo, revisitamos alguns preceitos da metalexicografia que embasam a discussão acerca dos dicionários e da sua relação com o hipertexto digital. Para tanto, a visão de que o dicionário é um texto-colônia contribui para compreender seu status atual no curso de uma possível reelaboração do meio impresso para o digital. Por fim, traçamos, em linhas gerais, uma análise contrastiva da rede léxico-semântica das obras selecionadas, a fim de responder à questão de pesquisa posta.

\section{Lexicografia teórica ou metalexicografia}

O fazer lexicográfico está intimamente ligado aos avanços das teorias da Linguística moderna. Desse modo, mais do que a simples confecção e elaboração de dicionários, a Lexicografia tem se dedicado a outros aspectos relativos a estas obras, como, por exemplo, o uso de dicionários escolares e a crítica que a eles se faz.

Fernández (2003, p. 38) chama atenção para o fato de que a "Lexicologia como disciplina científica abarcaria, pois, outros conteúdos como a teoria lexicográfica, a história da lexicografia, as investigações em torno do uso de dicionários e a crítica a eles". Tal definição dada pela autora parece reforçar a ideia de que essa disciplina se subdivide em duas partes: uma teórica e outra prática. 
v. 11 (esp.)

305-327 ago. 2021

A Lexicografia Teórica ou metalexicografia avançou muito, sobretudo no corrente século, dado o crescente interesse do público especializado ou não por obras lexicográficas que reflitam fidedignidade formal e conceitual. Assinala Martín (2000) que isso ocorre porque:

Em primeiro lugar há razões de tipo conjuntural: o aumento do número de estudantes, o desenvolvimento da Linguística, e de ramos como a Linguística Aplicada, o ensino-aprendizagem de línguas estrangeiras e os centros de ensino, assim como o desenvolvimento de grandes projetos lexicográficos (MARTÍN, 2000, p. 23).

A Lexicografia Teórica ou metalexicografia é um espaço multidisciplinar que absorve as contribuições que lhe são dadas pelas várias outras disciplinas da Linguística Moderna, tais como a Semântica, a Gramática e a Pragmática.

Para Pontes (2009, p. 5), as pesquisas que se baseiam nos métodos da Metalexicografia "servem de fundamentos sólidos para o fazer lexicográfico e para as discussões relativas à Lexicografia Aplicada". Esse ramo dá conta dos estudos do dicionário em sala de aula. O que mais tem se estudado nessa área são as atitudes e as crenças dos alunos diante dos dicionários, suas dificuldades de uso, as estratégias de leitura.

Outro ramo da Lexicografia que tem apresentadoum espetacular avanço é a Lexicografia Pedagógica ou Lexicografia Didática, que diz respeito às análises e às considerações feitas sobre o uso do dicionário como instrumento didático, voltado para um público definido e com uma finalidade específica: o ensino-aprendizagem de línguas.

\section{O dicionário}

O dicionário é o produto inacabado de toda a bagagem histórico-cultural e linguística de uma dada sociedade. Para muitos, este tipo de obra de referência concentra mesmo toda essa bagagem, porém os limites materiais e, sobretudo, imateriais para a produção de novos signos, e, por conseguinte, novos significados no mundo atual, tornam essa ideia mero devaneio romântico.

Embora a visão do senso comum sobre o que vem a ser um dicionário se baseie em uma relação binária entre a palavra e o seu significado, elencados ambos em um livro que contemple a solução de todas as dúvidas, os dicionários, desde sua mais remota utilização, transcendem a função de repositório de signos, cumprindo, a bem da verdade, funções comerciais e pedagógicas. 
Das listas comerciais sumérias, passando pelos grandes glossários medievais utilizados para a tradução de textos sagrados (FARIAS, 2007), até as obras de bolso com as quais lidamos hoje, é possível perceber que permanece intacto o tripé que sustenta a visão do que é um dicionário, a saber: sua relação com o espólio sócio-históricocultural de uma dada sociedade, as pressões comerciais, tanto na produção quanto na utilização destas obras de referência, bem como seu caráter intrinsicamente pedagógico.

Diversos autores seguem essa visão quando se trata de definir o que é o dicionário. Biderman (2003, p. 54), por exemplo, diz que "o conjunto dos usos sociais da língua estão refletidos no dicionário". Essa definição dialoga com o que postula Borba (2003, p. 303) ao dizer que o dicionário é o "arrolamento descritivo das propriedades do léxico em circulação na sociedade". Digamos, pois, que o dicionário é o depositário fiel da memória lexical de uma comunidade, descrevendo-a social e linguisticamente com base na "autoridade simbólica" que ela lhe confere.

Mas, embora essa "autoridade simbólica" dos dicionários os torne objetos de consulta por excelência, aos quais se recorre sempre que se precisa dirimir dúvidas, não é demais ponderar com Rey-Debove (1984, p. 63) que ele é "um dos objetos culturais mais usuais e mais mal conhecidos", o que nos parece um contrassenso, especialmente, nos tempos atuais da sociedade do conhecimento. E é neste mister do uso e do mau conhecimento sobre os dicionários, em especial de sua função pedagógica, que desenvolvemos este trabalho, partindo de uma inquietação acerca de como se organizam as redes medioestruturais de dicionários digitais e impressos.

Para tanto, é preciso encarar a obra lexicográfica em sua dimensão social, assim como em seus aspectos textual-discursivos. Alie-se a isso a função pedagógica que confere ao dicionário aspecto relevante. Não fosse isso, ele seria apenas mais um "baú" velho e empoeirado que guarda, mas não revela; cativa, mas não transforma. Seria o que, de maneira minimalista, define o dicionário Houaiss (2010, p. 258): "listagem, ger. em ordem alfabética, das palavras e expressões de uma língua ou um assunto com seus respectivos significados ou sua equivalência em outro idioma". Ou, nas lições do mestre Câmara Jr. (2009, p. 117), "lato sensu é qualquer registro metódico de formas linguísticas ou DIÇÕES, devidamente explicadas". Por nosso turno, reiteramos que a função pedagógica determina a própria constituição de um dicionário. 


\section{v. 11 (esp.)}

305-327 ago. 2021

Uns mais determinados, outros menos. Isso porque é na dinâmica de seu funcionamento discursivo que este tipo de obra se constrói.

Nesse sentido, aliamo-nos a Souto e Pascual (2003) quando caracterizam o dicionário em razão de sua propriedade eminentemente funcional e pedagógica:

Uma das propriedades essenciais do dicionário parece radicada em sua orientação prática e em sua finalidade didática; provavelmente, não duvidaria em afirmar que nos encontramos ante uma obra de consulta. Recorremos ao dicionário (especialmente aos dicionários linguísticos) habitualmente para solucionar problemas relativos ao léxico, sejam da natureza que sejam. Este uso determina a peculiar estrutura do texto dicionarístico. Os dicionários são textos constituídos por uma série de fontes entrelaçadas. O rico sistema de relações estabelecido entre as estruturas lexicográficas e suas próprias características dotam cada inventário de um perfil singular. Assim sendo, tampouco há a este respeito uma única proposta metalexicográfica para explicar como são os dicionários (SOUTO; PASCUAL, 2003, p. 57, grifos nossos).

Advogamos que é preciso definir as obras lexicográficas em razão de seu funcionamento textual-discursivo, visto que são obras "de consulta e não um texto para ser lido do começo ao fim" (REY-DEBOVE, 1984, p. 64) e que propiciam inter-relações entre os gêneros que as constituem, do mesmo modo como ocorre em relação aos textos que lhe serviram de fonte. A partir desta visão, podemos compreender o dicionário como uma colônia discursiva (HOEY, 2001) que abriga gêneros discursivos específicos.

\section{O dicionário como um texto-colônia}

Em face do exposto na seção anterior, assumimos a noção de que o dicionário é uma colônia discursiva (HOEY, 2001), visto que, enquanto discurso maior, abriga outros gêneros cuja dependência de significados, de estilo, de plano composicional e de propósito comunicativo concorrem para a constituição do objetivo maior deste tipo de obra.

Pontes (2009, p. 25) concebe o dicionário como gênero textual e, em razão disto, entende-o em conformidade com perspectivas de análise da Linguística Textual. Tal ponderação decorre certamente do fato de que, mesmo a leitura dos gêneros do dicionário, via de regra, sendo realizada por scanning (DIONíSIO, 2005), é possível afirmar que o dicionário possui uma tessitura própria, notadamente em sua medioestrutura. 
Fato é que, conforme aponta Dubois et al. (2006, p. 186), "o modo de leitura do dicionário é a consulta". Contudo, ela não se esgota neste gesto, posto que é apenas propulsora de toda uma cadeia de relações que compõe a colônia discursiva, o dicionário. A peculiaridade, pois, desta qualidade de texto, com caráter de colônia, reside no aspecto basilar de sua organização cartesiana, alfabética ou numerada, confrontando-se com a não linearidade de sua leitura (scanning).

Neste ponto, cabe perguntar: como a organização da rede léxico-semântica nos dicionários contribui para o sucesso da consulta? Qual a relação dos elos medioestruturais para o desenvolvimento do fluxo informacional entre os textos da colônia discursiva? Que papel tem o usuário na construção do projeto lexicográfico em dicionários digitais e/ou impressos? A expansão do alcance dos links, em relação às remissivas, proporciona um reajuste nas estratégias tradicionais de consulta?

Partindo do conceito de colônia discursiva (HOEY, 2001), que, ratificamos, norteará a visão que temos do que se possa denominar como o dicionário, com base em seu funcionamento discursivo, parecenos que, para responder a essas questões, será preciso ultrapassar o reconhecimento e o ordenamento alfabético das entradas ou o simples detectar de acepções diversas. Será necessário compreender como o consulente maneja os gêneros presentes na obra lexicográfica, seguindo as "pistas" deixadas pelo lexicógrafo, de modo a acompanhar o fluxo da informação.

Ademais, há outro ponto a ser considerado, que diz respeito aos dicionários em medium digital. Nestes já não há mais que se falar em ordem alfabética ou em "saltos" na leitura (scanning) de uma página a outra. A informática potencializou a dinâmica de consulta, tornando o acesso ao verbete, por exemplo, facilitado por um clique. Essa nova dinâmica implica um novo olhar para a forma como se dá a organização deste tipo de obra.

Dessa forma, tornamos a dizer que classificar o dicionário como "listagem de palavras" (HOUAISS, 2010, p. 258) é minimizar seu potencial textual-discursivo. Por outro lado, entendê-lo como uma colônia discursiva amplia o enfoque dado a este tipo de obra, tanto como autoridade simbólica que materializa a relação léxico-sociedade, quanto como imanentemente didático-informacional. Cada um desses aspectos são apresentados de forma mais ou menos saliente, a depender do tipo de dicionário utilizado pelo consulente. 
v. 11 (esp.)

305-327 ago.

2021
Dicionários eletrônicos

Para Pontes (2009, p. 54) dado o suporte, os dicionários podem ser classificados como "analógicos, convencionais ou estáticos - aqueles que têm formato de livro, o suporte mais tradicional e mais antigo dos dicionários; eletrônicos ou dinâmicos - classificados em online e off-line".

Tal classificação leva em conta os avanços atuais que a informática tem trazido para a lexicografia no tratamento dos dados, bem como em relação ao layout das obras digitais, no que tange ao ornamento e às funcionalidades. No século XXI, a lexicografia vive o intermédio entre o que ela foi e o que está se tornando. É dizer que, enquanto em outros tempos muitas discussões travadas no meio acadêmico diziam respeito ao aspecto da leitura vertical ou horizontal das obras lexicográficas, hoje, novas questões se apresentam. Dentre essas novas questões, cabe destacar a assunção de habilidades de consulta mais diversificadas, até porque os "novos" dicionários que circulam no meio eletrônico requerem estratégias as mais diversas para o acesso à informação.

As possibilidades de consulta são ampliadas nos dicionários eletrônicos e tornam automatizados certos gestos de consulta, como a busca em ordem alfabética e a relação entre os verbetes no dicionário, pois a economia gerada pela virtualidade do dicionário proporciona a realização de uma interação mais ampla dos artigos lexicográficos com outros gêneros discursivos que circulam em contextos reais de uso na web.

Tais potencialidades dos dicionários eletrônicos frente aos impressos são explicadas por De Schryver (2012) ao observar que a informática deu aos lexicógrafos a possibilidade de realizar muitos de seus sonhos. O tratamento informático do corpus e seu consequente armazenamento em bases de dados digitais é um deles, assim como as listas de palavras e/ou de materiais e fontes para a composição de obras lexicográficas, bem como os spellcheckers (ordenador alfabético) em programas de processamento de palavras (word-processing program) tão comuns em buscadores da internet e em SMS de smartphones.

De Schryver (2012) argumenta que, ao passo que as discussões na Academia se desenvolviam nas últimas décadas acerca das questões relativas à lexicologia e à lexicografia dos dicionários impressos (e ainda se desenvolvem), desde o final dos anos de 1960 já estavam sendo 
colocados em curso experimentos que visavam dar um tratamento automatizado à lexicografia. Entretanto, somente nos últimos anos da década de 1980 a comercialização de dicionários eletrônicos foi concretizada a partir da considerável quantidade de dados e fontes que os lexicógrafos conseguiram armazenar e manipular ao longo dos anos em fitas magnéticas. Isto redundou em uma base de dados considerável que pudesse fomentar programas de processamento da língua natural (Natural Language Processing - NLP).

De Schryver (2012) nos apresenta, mais detalhadamente, o percurso de desenvolvimento dos dicionários eletrônicos:

A princípio, os produtores de dicionários grandes criaram bases de dados genuínas para armazenar e manusear os dados de seus trabalhos de referência, o que significa que os pesquisadores da NLP pudessem utilizá-los (inclusive das primeiras fitas magnéticas) para popularizar os componentes lexicais de seus sistemas de NLP. O desenvolvimento destas bases de dados somado aos avanços do hardware, logicamente levou ao primeiro dicionário eletrônico, para leitura humana, voltado para o público em geral. De fato, do fim dos anos de 1980 até hoje, os dicionários eletrônicos têm sido acessados online (por assinatura ou não), em CD-ROM e outros discos, ou em aparelhos portáteis (DE SCHRYVER, 2012, p. 145).

Um dicionário eletrônico se define desta forma por conta do suporte eletrônico no qual ele é veiculado (on-line ou off-line) e pelo trato automatizado e virtual que ele proporciona a quem o produz e/ ou manuseia. Em contraponto, o dicionário impresso é veiculado em papel, o que o torna fisicamente concreto, pesado e impõe certos limites a seus produtores e leitores. Ademais, dicionários impressos requerem um trato manual, por parte de seus usuários, implicando a utilização de estratégias de consulta específicas para este fim.

Embora a comparação entre dicionários impressos e eletrônicos pareça sempre pender para as vantagens deste em detrimento daquele, esse juízo de valor é muito mais subjetivo e carregado de certo deslumbramento de quem vê a "revolução" digital como a invenção da roda.

Recorremos mais uma vez a De Schryver (2012) quando trata das vantagens dos incomparáveis dicionários impressos. Para ele, é um tanto deslumbrada a visão de que estes tipos de dicionário serão relegados a um segundo plano. O autor pondera que, mesmo com todo avanço tecnológico que temos experimentado, o 'dicionário' é um dos livros mais familiares, por seu valor simbólico, palpável e pelo prazer 


\section{v. 11 (esp.)}

305-327 ago. 2021

que causa. "Ele não cansa tanto a vista quanto os dicionários lidos na tela do computador"! (DE SCHRYVER, 2012, p. 152).

Há outros dois pontos destacados pelo mesmo autor com os quais concordamos, um até cômico e o outro pedagógico: o fato de que os dicionários impressos não precisam de tomadas e a possibilidade de o consulente poder riscá-los, destacando trechos e acrescentando seus comentários ao lado de informações relevantes. Eis aqui um aspecto digno de suscitar pesquisas sobre a relação consulente-dicionário.

\section{Hipertexto}

Com o advento da internet, muito se tem discutido sobre o fato de que o ambiente digital tenha inaugurado novas práticas discursivas. Esta visão, em geral, é compartilhada por estudiosos do hipertexto, como Lévy (1999) e Xavier (2003). De acordo com o posicionamento destes autores, vivemos uma revolução digital que influencia o próprio modo de interação atual do ser humano. Tal revolução está se concretizando nas práticas discursivas que se tornaram comuns com o aporte das funcionalidades das TIC.

Noutra direção, Snyder (2009) e Coscarelli (2009) advogam que as TIC têm um papel relevante nas formas digitais de interação, porém não inauguraram novas práticas discursivas. Na verdade, as TIC proporcionam dinamismo e uma leitura multifacetada, sem, entretanto, inaugurar uma nova forma de se comunicar. Há gestos específicos de leitura que se adaptam de gêneros discursivos que são reelaborados do meio impresso para o meio digital. A carta pessoal, por exemplo, é rememorada toda vez que se manda um e-mail, não em sua totalidade, mas em aspectos que familiarizam o produtor/leitor com a fronteira tênue entre o impresso e o digital.

O que seria, pois, o hipertexto? Textos impressos podem ser hipertextos? O dicionário, por exemplo, é um hipertexto? No dizer de Marcuschi (2001, p. 82), hipertexto "[...] é um espaço aberto sem margens nem fronteiras. [...] Não é mais linear nem se comporta numa direção definida". Se considerarmos que o texto impresso se caracteriza pela linearidade, a definição do autor limitaria o hipertexto ao espaço digital.

Xavier (2003, p. 284) aprofunda mais essa visão do hipertexto como "novidade" tecnológica, ao defini-lo como "um construto multienunciativo produzido e processado sobre a tela do computador". 
Estes posicionamentos que associam o hipertexto a algo revolucionário são debitários das ideias disseminadas pelo filósofo e engenheiro francês Pierre Lévy, no final do séc. XX. Tratando daquilo que ele denominara de "ciberespaço", que se descortinava ao ser humano em um período de incertezas (inclusive apocalípticas!), como o Bug do Milênio, advogava que "os hipertextos se tratavam, provavelmente, da maior revolução na história da escrita desde a invenção da própria escrita" (LÉVY, 1999, p. 44, grifo nosso).

Este viés revolucionário e otimista frente ao "ciberespaço" atinge a Linguística e outras esferas da atividade humana, como a organização política. Conforme Pinho (2011, p. 99), dado o ufanismo da virada de século e reverberado hoje na segunda década do séc. XXI, estaríamos prestes a viver "uma transformação radical da democracia representativa em democracia plebiscitária, suportada pelo aumento da participação dos cidadãos nas decisões dos governos, viabilizada pelo voto eletrônico".

O ufanismo frente ao "ciberespaço" tomou conta da vida humana em diversas vertentes. Mas, embora essas visões um tanto utópicas, por suposto, tenham sido fundamentais para abrir os caminhos para uma discussão mais centrada em aspectos objetivos, é interessante observar que essas ideias conseguem permanecer vivas hoje no imaginário dos mais deslumbrados. É óbvio que há algo novo, que alterou sobremaneira a atividade humana e, em especial, muitas de nossas práticas discursivas, porém isso não significa que o novo exclui os pilares que o fundamenta. Em outras palavras, o digital deve muito ao impresso.

Todo texto é, em última análise, um hipertexto, pois a principal característica deste é encontrada em maior ou menor escala, nos diferentes midia, dependendo do gênero discursivo que veicula. Um conto, por exemplo, pode até não parecer tão hipertextual quanto um verbete, visto que este estabelece suas ligações internas e externas, de maneira mais marcada lexicograficamente, levando seu leitor/consulente a um universo multilinear, ao passo que aquele não o faz dessa forma. Contudo, os contos também conduzem o leitor a um universo multilinear, ainda que tais pistas para esse universo não estejam explicitadas.

Seguimos a postulação proposta por Gualberto (2008) de distinguir, dentre os hipertextos, o digital: 


\section{v. 11 (esp.)}

305-327

ago.

2021
Embora possa parecer redundante, a opção por essa terminologia busca excluir discussões sobre hipertexto impresso como panfletos, propagandas, sumários, etc., e delimitar que o termo hipertexto será usado referindo-se a outros textos digitais que são conectados por meio de hiperlinks (GUALBERTO, 2008, p. 16).

Grosso modo, chegamos a uma definição de que o hipertexto digital tem por essência a sua ligação com outros textos por meio de hiperlinks que não apenas figuram como mecanismos linguísticos de entrelaçamento, mas também denotam aspectos sociocognitivos da leitura.

Nosso trabalho ancora-se no entendimento menos ufanista de que o hipertexto digital inova e cria realidades. Acreditamos que o hipertexto digital gera outros gestos de leitura, corroborando ponderações de Coscarelli e Ribeiro (2010), mas não descarta as estratégias que já eram utilizadas no impresso, fonte na qual o digital bebe com frequência.

\section{Hiperlink}

Comumente, os links são considerados os nós que vão entrelaçando o hipertexto digital a outros hipertextos ea outros conteúdos multimodais. Assim, pode-se falar sobre links que são verbais, ou seja, uma palavra ou enunciado que se destaca das demais por meio de um decalque de cor de fonte diferente das demais (geralmente, utilizase a cor azul); pode figurar de forma mais chamativa, dependendo da intenção do autor do texto de conduzir o leitor por sua trilha; há os links não-verbais, quer dizer, aqueles que aparecem como ilustração, imagem, vídeo, áudio ou iconografia.

Embora se apresentem de maneiras diversas, os hiperlinks ou, simplesmente, links cumprem a função de conduzir o leitor pelas trilhas multilineares da leitura do hipertexto digital. Ao clicar em um link, o leitor abre novas páginas relacionadas à temática daquela que primeiro consultou, estabelecendo, assim, um direcionamento informacional que, no mais das vezes, transcende a própria vontade do desenvolvedor da página.

Nesse sentido, a construção da unidade temática, se é que ela existe nos hipertextos digitais, depende mais da vontade do leitor que das pistas deixadas pelo autor. Há componentes sociocognitivos que influenciam a produção e o acesso aos links, contudo não nos cabe discuti-los neste trabalho. 
Resgatamos a noção de hipertexto postulada por Koch (2004), posto que cada um dos pontos destacados tenha como índice linguístico de sua ocorrência os hiperlinks:

1. não-linearidade (geralmente considerada a característica central);

2. volatilidade, devida à própria natureza (virtual) do suporte;

3. espacialidade topográfica, por se tratar de um espaço de escritura/leitura sem limites definidos, não hierárquicos, nem tópico;

4. fragmentariedade, visto que não possui um centro regulador imanente;

5. multissemiose, por viabilizar a absorção de diferentes aportes sígnicos e sensoriais numa mesma superfície de leitura (palavras, ícones, efeitos sonoros, tabelas tridimensionais);

6. interatividade, devido à relação contínua do leitor com múltiplos autores praticamente em superposição e em tempo real;

7. iteratividade, em decorrência de sua natureza polifônica e intertextual;

8. descentração, em virtude de um desdobramento indefinido de tópicos, embora não se trate, é claro, de um agregado aleatório de fragmentos textuais (KOCH, 2004, p. 64).

Como se percebe, o hiperlink é inerente ao próprio hipertexto digital e não seria demais dizer que ele é a materialidade linguística que torna possível o funcionamento de cada um dos aspectos descritos por Koch (2004). Especialmente em relação ao ponto 8, acreditamos que links e remissivas, nos dicionários, cumprem a mesma função de levar o consulente de um lugar a outro, sem, contudo, que estes movimentos sejam essencialmente difusos, pois seguem o fluxo informacional préestabelecido pela palavra-entrada. Ainda que a função primeira dos links seja a descrita acima, na velocidade de um clique, há que se destacar que eles estabelecem teias informacionais, relações entre blocos textuais e entre as diferentes vozes que emergem no discurso.

Em última análise, o conceito de link com o qual trabalhamos neste estudo é o que o define como elo necessário ao estabelecimento das relações multilineares e multimodais no hipertexto digital. Tais elos conduzem de maneira dinâmica o leitor por informações compartilhadas entre este e o autor, em um vai-e-vem informático dos diversos textos e das diversas vozes que ecoam na rede para construir os sentidos do texto. 
v. 11 (esp.)

305-327

ago.

2021

\section{Contrastando redes medioestruturais: links e remissivas}

Com base em corpus constituído por trinta verbetes de cada um dos dois dicionários escolares selecionados para o desenvolvimento de nossa tese de doutoramento, buscamos descrever a rede de remissivas de cada um deles a partir de dados concretos presentes em sua microestrutura, bem como estabelecer as comparações necessárias no que se refere à organização medioestrutural de dois dicionários escolares, em meio impresso, e dois em meio digital.

Para tanto, o estabelecimento das microestruturas abstratas dos verbetes das obras em questão, quais sejam, Mini Aurélio Jr. (2005) e Mini Houaiss (2004), ambos impressos, e, os eletrônicos on-line, Aulete Digital e Priberam dicionário on-line de língua portuguesa, estes de acesso irrestrito e gratuito, são fundamentais para análise, conforme se pode observar na seção a seguir.

\section{Sub-rede do verbete BASE no Mini Aurélio Jr. (2005)}

Figura 01 - Microestrutura e verbete base

\section{Microestrutura abstrata:}

Palavra-entrada + categoria gramatical + flexão de gênero + paradigma(s) definicional(is) + lexia(s) complexa(s) + remissiva + lexia complexa + abonação

Ba.se subst. fem. 1. Tudo quanto serve de fundamento ou apoio. 2. Parte inferior onde alguma coisa repousa ou se apóia. 3. Parte inferior de coluna, pilar, etc. 4. Origem, fundamento. 5. Preparo intelectual. 6.Ingrediente ou substância principal de uma mistura. 7. Conjunto de construções e instalações militares destinadas a prestar apoio às unidades que operam em determinada área. 8. Eletrôn. Estreita região entre o emissor e o coletor, num transmissor bipolar. 9. Gram. Radical (5). 10. Mat. Num sistema de logaritmos, o número constante que, elevado ao logaritmo de outro, reproduz este outro. 11. Quím. Substância que reage com um ácido para dar um sal, que se dissocia em água formando íons hidroxila (HO), que é capaz de aceitar um próton e que pode doar um par de elétrons. • Base de dados. Inform. Banco de dados (1). Base espacial. Centro de lançamento de foguetes e satélites. Base ortonormal. V. ortonormal. Tremer nas bases. 1. Bras. Sentir-se seriamente ameaçado; ter muito medo. 2.Ficar fortemente impressionado: Ao ver a beleza da moça, tremeu nas bases.

Fonte: Mini Aurélio Jr. (2005).

No que se refere ao verbete BASE, podemos observar a ocorrência de uma remissão facultativa marcada pela sigla V.. Esta remissão diz respeito à palavra ortonormal, que é parte da lexia complexa BASE ORTONORMAL. É comum o fato de que muitos usuários de dicionários buscam no ato da consulta muito mais informações do que inicialmente buscavam. Ao consultar uma palavra em um dicionário, o consulente pode deparar-se com uma nova demanda por significados 
que complementem e esclareçam melhor o significado que buscavam a priori. Esse é um aspecto natural da consulta a dicionários e demonstra que o fluxo das informações no interior dos verbetes é contínuo.

Ao que parece, a referência à palavra ortonormal reforça ainda mais a necessidade de que a informação inicial da definição da palavra BASE requer um complemento, justamente porque a lexia complexa formada - BASE ORTONORMAL - assume um novo significado. Porém, no Mini Aurélio Jr. (2005), o usuário que desejar expandir os seus conhecimentos, em relação ao que vem a ser BASE ORTONORMAL, não poderá fazê-lo, visto que a palavra ortonormal não consta na nomenclatura da referida obra.

Assim, podemos afirmar que ocorre neste caso uma quebra no fluxo de informações do verbete BASE, pelo fato de que a remissiva $V$. ortonormal constitui uma pista falsa, ou seja, remete o consulente de um verbete a outro, sem que haja na nomenclatura do dicionário um verbete correspondente a essa remissão.

\section{Sub-rede do verbete BASE no Dicionário Aulete Digital}

Figura 02 - Microestrutura e verbete base do Dicionário Aulete Digital

\section{Microestrutura abstrata:}

Palavra-entrada + pronúncia + categoria gramatical + flexăo de gênero + paradigma definicional $1+$ abonação + marca de uso + paradigma definicional $2+$ lexia complexa + marca de uso + paradigma definicional $3+$ paradigma definicional $4+$ lexia complexa + maca de uso + paradigma definicional $5+$ marca de uso + paradigma definicional $6+$ paradigma definicional $7+$ lexia complexa + marca de uso + paradigma definicional $8+$ lexia complexa + marca de uso + paradigma definicional 9 + lexia complexa + lexia complexa + paradigma definicional $10+$ abonação + marca de uso + paradigma definicional $11+$ marca de uso + paradigma definicional + exemplo + paradigma definicional $13+$ exemplo + marca de uso + paradigma definicional $14+$ paradigma definicional $15+$ exemplo + paradigma definicional $16+$

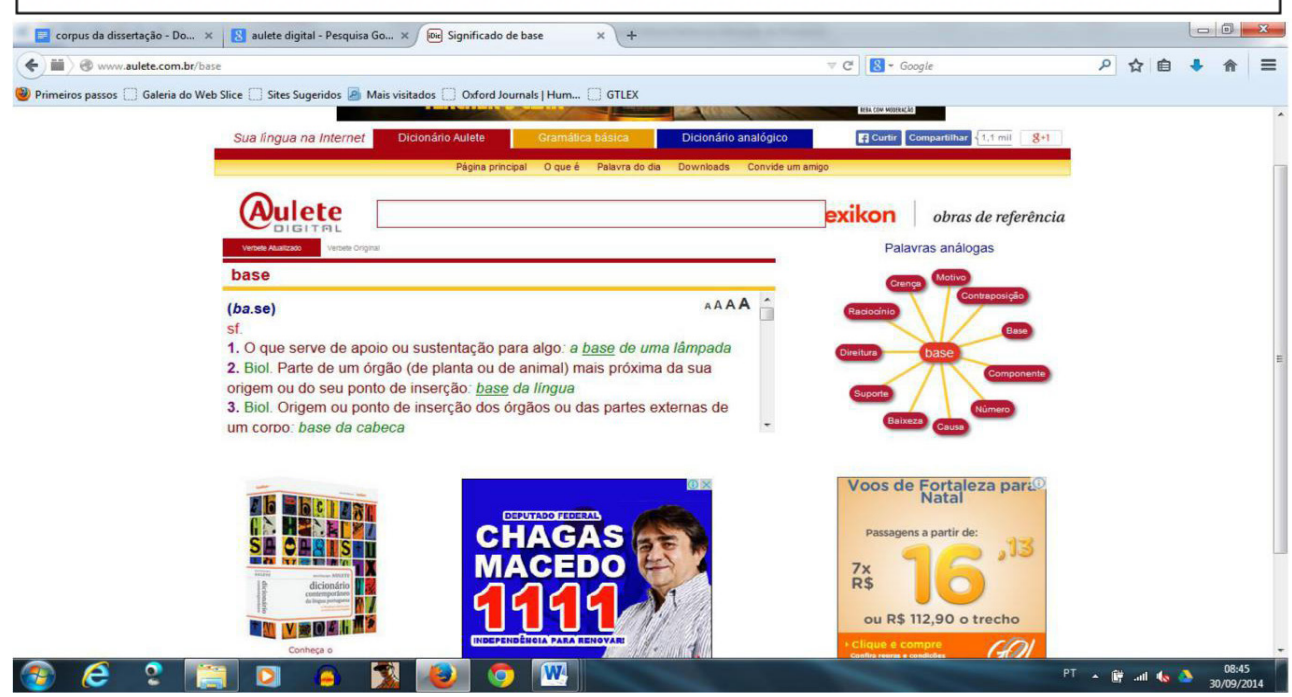

Fonte: Aulete Digital (s.d.). 
V. 11 (esp.)

305-327 ago. 2021

O fato de que este dicionário prima por marcas de uso e exemplos pode evidenciar que há um direcionamento de sua constituição para consulentes que busquem o dicionário no intuito de melhorar a sua produção escrita, haja vista que os exemplos no texto lexicográfico, mais do que contribuir para a compreensão global da palavra requerida, encorpam o vocabulário internalizado do usuário, por apresentar situações discursivas comuns e com as quais ele possa se deparar. No que tange às remissivas no verbete em tela, não há inovações em relação aos verbetes impressos já analisados anteriormente. Ao contrário, a impressão é de que foi realizado um copy and paste da versão impressa do Dicionário Caldas Aulete.

O artigo lexicográfico analisado do Dicionário Aulete Digital está circundado de diversos links publicitários e até de propaganda política, típico dos hipertextos digitais. Essa multifusão de assuntos não contempla a real necessidade lexicográfica do consulente. Traço de uma possível reelaboração do gênero verbete neste dicionário se encontra no lado direito do verbete com um diagrama, linkando a palavra-entrada a outras análogas a ela. Essa ligação gera diversas sub-redes de remissivas que se atualizam a cada novo clique. Neste caso, links e remissivas são sincronizados em um só mecanismo textual-discursivo que caracteriza o texto do dicionário digital.

Além do mais, como dicionário digital, o Dicionário Aulete Digital investe pouco em inovações informáticas, como a utilização de palavras como links ou da sincronização destes com as remissivas. Dicionários on-line utilizam-se destes expedientes para favorecer o fluxo da informação. O que o Dicionário Aulete Digital faz é destacar algumas lexias complexas na cor azul. O que gera certa confusão e frustração, pois a maioria dos usuários de hipertextos digitais, hoje, associa palavras destacadas em cores diversas num enunciado on-line como um link, mas isso não ocorre no corpo dos verbetes do dicionário em estudo.

Como se pode observar na amostra apresentada, o leque que se abre, a partir de uma simples consulta ao dicionário, é um tanto imprevisível, haja vista que depende dos direcionamentos do lexicógrafo, assim como do próprio nível de letramento digital, e, por que não dizer, lexicográfico do consulente. Em linhas gerais, dado o espaço do gênero artigo, discutiremos adiante elementos que verificamos em trabalho mais amplo que servirão para lançar alguma luz sobre a questão de investigação norteadora de nossa pesquisa. 
Da sistematicidade das redes de remissivas

Sob o prisma dos questionamentos preliminares que fizemos acerca da organização medioestrutural dos dois dicionários objetos de nosso estudo e tendo como direcionamento os preceitos teóricometodológicos da metalexicografia, constatamos que:

- Não há sistematicidade rigorosa na medioestrutura dos dois dicionários;

- A falta de sistematicidade e as pistas falsas comprometem o fluxo contínuo da informação.

- Links e remissivas possuem a mesma funcionalidade nos dicionários impressos e nos dicionários eletrônicos on-line.

As constatações acima elencadas apresentam alguns desdobramentos relevantes para a análise proposta neste artigo. Apresentamos, pois, tais desdobramentos.

A primeira constatação, por exemplo, que se refere ao fazer lexicográfico propriamente dito, toma como norte a qualidade das remissões constantes nos dois dicionários em estudo:

a) As remissões são, em geral, facultativas e se limitam apenas ao interior dos verbetes, sendo raras as referências aos textos externos e às fontes de consulta do lexicógrafo. Esse é um aspecto relevante, especialmente no que diz respeito aos verbos, tendo em vista que eles são apresentados na nomenclatura em sua forma infinita, mas a demanda do consulente, na maioria das vezes, é por sua forma declinada. Por isso mesmo, partimos do princípio de que são necessárias as remissões às listas de conjugação de verbos, que devem compor os textos externos dos dicionários escolares; ademais, a utilização de diferentes índices para estabelecer a remissão entre os verbetes pode comprometer a percepção, por parte do consulente, de como se organiza a medioestrutura nos dicionários em questão, sobretudo se estes índices não forem previamente explicados nos textos iniciais do dicionário; 


\section{v. 11 (esp.)}

305-327 ago. 2021

b) A linguagem não é clara, apresentando nas acepções termos de significado desconhecido e marcados por índices de remissão facultativa, levando, desta forma, o consulente a ter de consultar vários verbetes, a fim de conseguir a informação inicialmente pretendida, o que caracteriza a circularidade nas definições. Esse, na verdade, é outro fator que demonstra a qualidade ou não de uma obra lexicográfica, visto que quem a consulta, sobretudo estudantes, busca a informação de forma rápida e dinâmica;

c) Nos dicionários escolares on-line, os links dinamizam a rede medioestrutural, proporcionando desdobramentos multilineares do fluxo informacional, especialmente, na remissão a gêneros digitais. A funcionalidade dos links se percebe quando torna remissivas obrigatórias facilmente acessíveis em um clique ou quando conduzem o consulente a modelos de conjugação verbal. Além disso, a quantidade de remissivas facultativas é ampliada, pois os dicionários escolares on-line não têm as limitações físicas nem financeiras do papel.

Vale ressaltar que as distinções em relação à forma de se fazer as remissões, nos dicionários Mini Aurélio (2005) e Mini Houaiss (2004), evidenciam certo distanciamento destas obras frente aos preceitos teóricos da Lexicografia, no que concerne à produção de obras lexicográficas. É preciso considerar a ideia de que a padronização das remissões favorece a uma maior eficácia na consulta do usuário.

Com relação à segunda constatação, podemos afirmar que deve fazer parte do plano inicial do lexicógrafo, ao produzir um dicionário, o cuidado em observar se os direcionamentos dados no interior do verbete por meio de remissivas levam realmente a informações que constem na obra, quer sejam referentes a outros verbetes, quer sejam referentes aos textos externos. Essa observação é importante pois os termos que integram as diferentes acepções nem sempre constam na nomenclatura dos dicionários.

Partindo do princípio de que o dicionário deve suprir uma busca por informação, não é previsível, por parte de quem o consulta, que não terá sua demanda suprida. Nesse sentido, as pistas falsas se 
apresentam como um elemento complicador e até desmotivador para o consulente, evidenciando um aspecto negativo das obras lexicográficas analisadas. No entanto, as pistas falsas podem evidenciar muito mais uma pressão de mercado sobre o lexicógrafo do que uma falta de zelo, para que este venha a "reaproveitar" verbetes de um dicionário geral, fazendo alguns "recortes" a fim de adequá-los aos limites de um dicionário escolar.

Constatamos, por fim, que links e remissivas possuem, grosso modo, a mesma função de levar o consulente de um lugar a outro. Para o escopo de nosso trabalho, essa constatação é validada pela análise de aspectos lexicográficos das obras em questão. A rede medioestrutural dos verbetes analisados nos dicionários eletrônicos on-line apresenta remissivas que não são demarcadas por V. ou Cf., mas por links que atualizam na tela a informação demandada. Tais links figuram internamente aos verbetes, em suas acepções, nos exemplos presentes no uso da palavra-entrada em redes sociais e outras páginas da web. Portanto, a despeito da questão da automatização da busca, não há que se tratar de diferenças significativas entre links e remissivas nos verbetes digitais, que os tornem oriundos de práticas discursivas distintas. Talvez, uma análise ancorada na Linguística do Texto e na Pragmática possa refutar essa visão, porém não é esse o foco dessa pesquisa.

Desenvolvemos nossa análise levando em conta o plano inicial dos lexicógrafos que compuseram as obras em estudo. Este plano é evidenciado pela configuração da microestrutura abstrata dos verbetes dos dicionários Mini Aurélio (2005) e Mini Houaiss (2004), um expediente fundamental para a organização de qualquer obra lexicográfica, visto que ela serve de fundamento para que se desenvolva um padrão estrutural para os verbetes dos dicionários, bem como para a formação e o letramento dos estudantes e dos professores de língua materna.

\section{Considerações finais}

Levando-se em conta nossa hipótese básica de que a falta de sistematicidade nas remissões e a má qualidade das definições acabam gerando problemas no ato da consulta do aluno/consulente, podemos afirmar que os dados coletados confirmam essa premissa, tendo em vista que, em diversos verbetes, tanto do Mini Aurélio (2005) quanto do 


\section{v. 11 (esp.)}

305-327 ago. 2021

Mini Houaiss (2004), constatamos a presença de índices de remissão diferentes. Tal variação, a nosso ver, dificulta o rápido acesso à informação, pois alguns índices remissivos não são descritos nos textos iniciais dos dois dicionários escolares.

Entendemos que seja necessário um maior cuidado por parte do lexicógrafo em relação à medioestrutura do dicionário, uma vez que as remissivas refletem a teia de informações formada pela relação entre os diferentes artigos léxicos de mesmo campo semântico e as referências aos textos externos. Caso não haja o claro entendimento acerca dos índices remissivos do dicionário, compromete-se o fluxo da informação ao longo do dicionário.

Este fato por si só não seria suficiente para atestar a dificuldade na consulta aos dicionários, no entanto, como estes índices aparecem ao longo da medioestrutura dos dicionários em questão, é necessário que sejam especificados previamente nos textos iniciais que compõem a obra, exatamente o contrário do que ocorre no Mini Aurélio (2005) e no Mini Houaiss (2004), sendo este último um pouco menos negligente a esse respeito. Destaque-se ainda a ausência de uma explicação prévia sobre o uso dos diferentes índices remissivos, pois nos dois dicionários escolares analisados só se faz referência a um tipo de índice. Além disso, o não esclarecimento dos mecanismos de remissão obrigatória, no caso, principalmente, de definição por sinonímia, pode gerar dúvida ao aluno/consulente.

Todavia, o mais grave em relação à organização medioestrutural nos dois dicionários refere-se às pistas falsas, que são as ocorrências em que o verbete para o qual o aluno/consulente é direcionado não consta na macroestrutura do dicionário. Pelo que percebemos, com base nos dados que foram analisados, a pista falsa é muito mais comum ao longo das duas obras em estudo do que poderia ser aceitável, tendo em vista que o fato de um usuário buscar uma palavra e não a encontrar constitui enorme frustração, pois quebra o fluxo da informação inicialmente pretendida.

Há ainda a circularidade que reflete a não progressão das informações ao longo dos dicionários escolares, pois a motivação maior de qualquer aluno/consulente ao consultar um dicionário é a busca por informações novas. Ao invés disso, algumas remissões "devolvem" o usuário ao ponto de partida sem esclarecer a sua dúvida. No nosso ponto de vista, a circularidade juntamente com as pistas falsas constituem as duas maiores deficiências que a medioestrutura de um dicionário pode apresentar, sobretudo os escolares. 
Com base em nossas análises, não podemos afirmar qual dos dois dicionários é o "melhor", nem foi esse o objetivo de nosso estudo, mas é possível apontar algumas falhas, que, talvez por conta de pressões de mercado ou por conta mesmo de um constante aperfeiçoamento, precisam ser, se não totalmente eliminadas, pelo menos reduzidas a um nível aceitável, prejudicando o mínimo possível aquele a quem o dicionário se destina, o estudante.

Ademais, advogamos a relevância de que os consultores do Ministério da Educação (MEC) levem em conta a análise da medioestrutura como um dos critérios para atestar a qualidade dos dicionários que serão distribuídos para alunos das escolas públicas brasileiras, pois, certamente, os lexicógrafos lançarão um olhar muito mais atento ao estudo da medioestrutura dos dicionários escolares. Portanto, nossa pesquisa cumpre função de ser motivadora para outras que busquem avaliar a eficácia das remissivas em relação ao desenvolvimento da leitura e da escrita, bem como as semelhanças e diferenças entre as remissivas e os links, nos hipertextos, estabelecendo-se uma interface entre os estudos lexicográficos e os estudos sobre o hipertexto.

Este empreendimento investigativo visou, sobretudo, contribuir para a discussão da medioestrutura nas obras lexicográficas, tão parcamente abordada na literatura linguística no Brasil. Ademais, o reconhecimento do papel que desempenham as remissivas em textoscolônia ultrapassa os limites da metalexicografia, haja vista que o desenvolvimento de práticas discursivas que envolvam remissivas favorece a noção de que é preciso fomentar um tipo específico de letramento, o lexicográfico, para dar conta das ações dos consulentes frente à leitura das supracitadas obras. Neste sentido, acreditamos que, ao demonstrar a intrínseca relação de links e remissivas no texto lexicográfico, inserimo-nos no grupo dos que, passado o deslumbre inicial das TIC, lançam um olhar mais racional sobre as ações linguageiras que se dão no meio digital.

\section{Referências}

AULETE, C. Aulete digital - dicionário contemporâneo da língua portuguesa. Dicionário Caldas Auletes, vs. On-line. Disponível em: http://www.aulete. com.br/base. Acesso em: 15 jun. 2015.

BIDERMAN, M. T.C. Dicionários do Português: daTradiçãoàContemporaneidade. Alfa, Araraquara, v. 47, n. 1, 2003, p. 53-69. Disponivel em: http://seer.fclar. unesp.br/alfa/article/view/4232. Acesso em: 15 jun. 2015. 
v. 11 (esp.)

305-327 ago. 2021

BORBA, F. da S. Organização de Dicionários: uma introdução à lexicografia. São Paulo: Editora UNESP, 2003.

CÂMARA JR., J. M. Dicionário de Linguística e Gramática: referente à língua portuguesa. 27. ed., Petrópolis: Vozes, 2009.

COSCARELLI, C. V. Textos e Hipertextos: procurando o equilíbrio. Linguagem em (Dis)curso, Palhoça, v. 9, n. 3, p. 549-564, 2009. Disponível em: https:// wWw.scielo.br/scielo.php?pid=S1518-76322009000300006\&script $=$ sci abstract\&tlng=es. Acesso em: 15 jun. 2015.

COSCARELLI, C. V.; RIBEIRO, A. E. Leitura: um processo cada vez mais complexo. Letras de Hoje, v. 45, n. 3, p. 35-42, 2010. Disponível em: https:// revistaseletronicas.pucrs.br/index.php/fale/article/view/8118. Acesso em: 15 jun. 2015.

DANTAS, H. O. Estudo da Rede de Remissivas em Dicionários Escolares. 2009. Dissertação (Mestrado em Linguística) - Programa de Pós-Graduação em Linguística, Universidade Federal do Ceará, Fortaleza, 2009.

DE SCHRYVER, G. Lexicographers' Dreams in the Electronic- Dictionary Age. International Journal of Lexicography, Oxford, v. 16, n. 2, p. 143-199, 2012. Disponívelem:https://academic.oup.com/ijl/article-abstract/16/2/143/925134. Acesso em: 15 jun. 2015.

Dicionário Priberam da Língua Portuguesa (2008-2021). Versão on-line organizada pela Priberam Informática s/a. Disponível em: https://dicionario. priberam.org. Acesso em: 15 jun. 2015.

DIONISIO, A. P. Gêneros multimodais e multiletramento. In: KARWOSKI, A.M.; GAYDECZKA, B.; BRITO, K.S. (org.). Gêneros textuais: reflexões e ensino. Palmas e união da Vitoria, PR: Kaygangue, 2005.

DUBOIS, J. et allii. Dicionário de Linguística. São Paulo: Cultrix, 2006.

FARIAS, E. M. P. Breve História do Fazer Lexicográfico. Revista TRAMA, Curitiba, no 5, v. 3, p. 89-97, 2007. Disponível em: http://e-revista.unioeste. br/index.php/trama/article/view/961. Acesso em: 15 jun. 2015.

FERNÁNDEZ, D. A. La Lexicografia como Disciplina Linguística. In: GUERRA, A. M. M. (org.). Lexicografia Española. Barcelona: Ariel Linguística, 2003, p. $31-52$.

FERREIRA, A. B. de H. Dicionário Aurélio Júnior: dicionário escolar da língua portuguesa. Curitiba: Positivo, 2005.

GUALBERTO, I. M. T. A influência dos hiperlinks na leitura de hipertexto enciclopédico digital. 2008. Tese. (Doutorado em Linguística). Faculdade de Letras, Universidade Federal de Minas Gerais, Belo Horizonte, 2012.

HOEY, M. Textual Interaction: an introduction to written discourse analysis. London: Routledge, 2001.

KOCH, I. G. V. Introdução à linguística textual: trajetória e grandes temas. São Paulo: Martins Fontes, 2004. 
LÉVY, P. A revolução contemporânea em matéria de comunicação. In: Para navegar no século XXI: tecnologias do imaginário e cibercultura. V. 2. São Paulo: EDIPUCRS, 1999, p. 195-216.

MARCUSCHI, L. A. O hipertexto como um novo espaço de escrita em sala de aula. Linguagem \& Ensino, São Paulo, v. 4, n. 1, p. 79-111, 2001. Disponível em: https://periodicos.ufpel.edu.br/ojs2/index.php/rle/article/view/15529. Acesso em: 15 jun. 2015.

MARTÍN, M. C. A. El Diccionario en el Aula. Granada: Editora de la Universidad de Granada, 2000.

MINIDICIONÁRIO Houaiss da língua portuguesa. Organizado pelo Instituto Antônio Houaiss de Lexicografia e Banco de Dados da Língua Portuguesa S/C Ltda. - 2. ed. rev. e aum. - Rio de Janeiro: Objetiva, 2004.

PINHO, J. A. G. de. Sociedade da informação, capitalismo e sociedade civil: reflexões sobre política, internet e democracia na realidade brasileira. Revista de Administração de empresas, v. 51, n. 1, p. 98106, 2011. Disponível em: https://www.scielo.br/scielo.php?script=sci arttext\&pid=S0034-75902011000100009. Acesso em: 15 jun. 2015.

PONTES, A. L. Dicionário para Uso Escolar: o que é e como se lê. Fortaleza: EDUECE, 2009.

REY-DEBOVE, J. Léxico e dicionário. Alfa, São Paulo, n. 28 (supl.), p. 45-69, 1984. Disponivel em: https://periodicos.fclar.unesp.br/alfa/article/view/3678. Acesso em: 15 jun. 2015.

SNYDER, I. Ame-os ou deixe-os: navegando no panorama dos letramentos em tempos digitais. In: ARAÚJO, J. C.; DIEB, M. (org.) Letramentos na Web: gêneros, interação e ensino. Fortaleza: EDUFC, 2009, p. 23-46.

SOUTO, M. C.; PASCUAL, J. I. P. P. El Diccionario y otros Productos Lexicográficos. In: GUERRA, A. M. M. (org.) Lexicografía Española. Barcelona: Editora Ariel, 2003, p. 53-78.

XAVIER, A. C. Hipertexto e intertextualidade. Cadernos de estudos linguísticos, n. 44, p. 283-290, 2003. Disponível em: https://periodicos.sbu.unicamp.br/ ojs/index.php/cel/article/view/8637082. Acesso em: 15 jun. 2015. 